\title{
Technical and patient-related sources of error and artifacts in bone mineral densitometry using dual-energy X-ray absorptiometry: A pictorial review
}

\author{
Mohsen Qutbi, Mehdi Soltanshahi, Yaser Shiravand, Saba Karami Gorzi ${ }^{1}$, Babak Shafiei, \\ Isa Neshandar Asli \\ Department of Nuclear Medicine, Taleghani Educational Hospital, School of Medicine, Shahid Beheshti University of Medical \\ Sciences, Tehran, 'Science and Research Branch, Islamic Azad University, Tehran, Iran
}

Correspondence: Dr. Mohsen Qutbi, Department of Nuclear Medicine, Taleghani Hospital, Yaman St., Velenjak, Tehran 1985711151, Iran. E-mail:mohsen.qutbi@gmail.com, mohsen.qutbi@sbmu.ac.ir

\begin{abstract}
Dual-energy X-ray absorptiometry is currently the standard and validated tool for measurement of bone mineral density and for the evaluation of osteoporosis. Current densitometry scanners based on dual-energy X-ray absorptiometry method produce two X-ray beams with different energies to differentiate the overlapped soft tissue and bony structures, by creating two different attenuation profiles. Procedural guidelines are available to technicians and physicians to guarantee the best practice, including consistent positioning during scanning and standard reporting. However, similar to other imaging modalities, dual-energy $\mathrm{X}$-ray absorptiometry may be influenced by technical errors, and thus, imaging artifacts may arise and accuracy and precision of the results may be influenced. This issue may, in turn, affect the final result and interpretation. Hence, the article is arranged with the intention of presenting some less common and rare technical and patient-related sources of error and resultant artifacts, from poor patient preparation to acquisition and data processing. Where appropriate, the corresponding tables of densitometric results (bone mineral density) and statistical parameters ( $T$ - and Z-scores) are provided.
\end{abstract}

Key words: Artifact, atlas, bone mineral densitometry, dual-energy X-ray absorptiometry

\section{Introduction}

The present article offers an illustrated compendium of technical and patient-related sources of error and resultant artifacts in dual-energy X-ray absorptiometry (DXA) with a potential impact on patient care in daily practice. In addition to images provided for recognition of artifacts, the pertinent results are also presented to offer the reader

\begin{tabular}{|l|l|}
\hline \multicolumn{2}{|c|}{ Access this article online } \\
\hline Quick Response Code: & \\
\hline & Website: \\
& www.ijri.org \\
& DOI: \\
& $10.4103 /$ ijri.IJRI_495_19 \\
\hline
\end{tabular}

a head-to-head comparison as well as the effect of those artifacts on densitometric results. These factors with their potential impact are summarized and tabulated in Table 1.

This is an open access journal, and articles are distributed under the terms of the Creative Commons Attribution-NonCommercial-ShareAlike 4.0 License, which allows others to remix, tweak, and build upon the work non-commercially, as long as appropriate credit is given and the new creations are licensed under the identical terms.

For reprints contact: WKHLRPMedknow_reprints@wolterskluwer.com

Cite this article as: Qutbi M, Soltanshahi M, Shiravand Y, Gorzi SK, Shafiei B, Asli IN. Technical and patient-related sources of error and artifacts in bone mineral densitometry using dual-energy $\mathrm{X}$-ray absorptiometry: A pictorial review. Indian J Radiol Imaging 2020;30:362-71.

Received: 05-Jan-2020 Accepted: 28-May-2020

Revised: 31-Mar-2020 Published: $15-$ Oct-2020 
Table 1: Summary of factors influencing the results of DXA scan with their potential impact and misdiagnosis

Source of error
Patient preparation and conditions/issues before scan
Metallic objects in or attached to body/garments
Retained barium in bowels
Ankylosing spondylitis

Metastatic lesions in skeleton

Vertebral compression fracture and vertebroplasty

\section{Laminectomy \\ Scan acquisition \\ Positioning}

Motion

Image noise

Data processing

Problems with calibration using phantoms

Error in patient data entry

ROI placement and bone map error
Potential impact and misdiagnosis

High-density materials falsely increase BMD values due to higher radiation attenuation

Error in BMD measurement of lumbar spine if overlapped on the vertebrae

Erroneous measurement of BMD of the spine if significant calcification and sclerosis of perispinal ligaments and soft tissue are present

Difficulty in labeling of vertebrae in severe forms

Increase in BMD in areas involved with metastasis from osteoblastic tumors

Decrease in vertebral height and conversely increase in mineral density if compression fracture exists Unusually high vertebral BMD and statistical indices as well as blackening of vertebra on the DXA image in vertebroplasty

Decrease in BMD of lumbar vertebrae due to removal of bony structures

Changes in BMD values and diagnosis

Inconsistency of measurements in serial studies

Higher likelihood of motion during scanning

Visualized as a single break or one with regular pattern

Error in bone mapping and BMD measurements

Uncertainty in measurements of the lumbar spine BMD, in particular, in obese patients

Systematic inaccuracy in measurements, if calibration factor not properly set during installation or service Incorrect selection of normal reference database according to patient age, gender, and ethnicity, thus erroneous statistical indices provided

Error in BMD of vertebrae due to incorrect labeling

Change in BMD of a bone or bone subregion by both erroneous soft tissue inclusion or bone exclusion during bone mapping

Diminished reproducibility

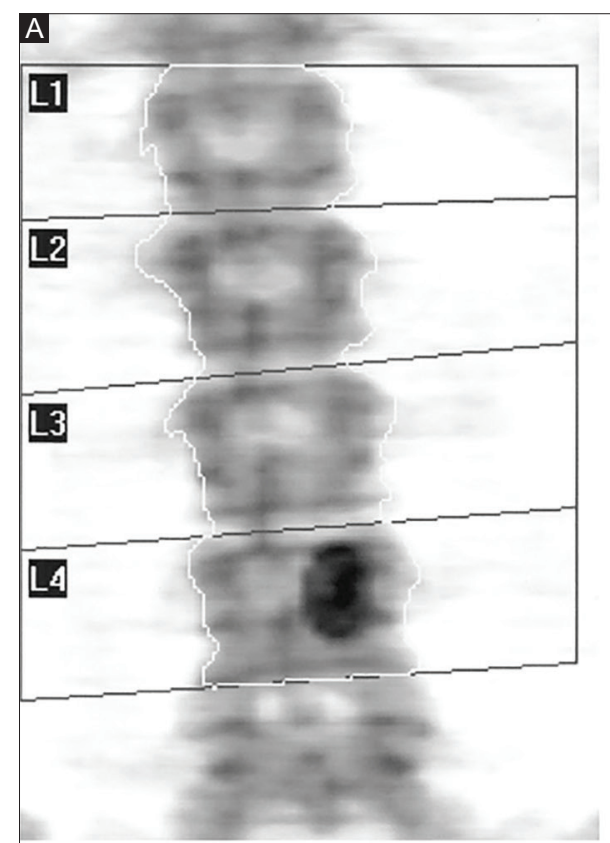

DXA Results Summary:

\begin{tabular}{|lccrrrrr|}
\hline Region & $\begin{array}{c}\text { Area } \\
\left(\mathbf{c m}^{2}\right)\end{array}$ & $\begin{array}{r}\text { BMC } \\
(\mathbf{g})\end{array}$ & $\begin{array}{c}\mathbf{B M D} \\
\left(\mathbf{g} / \mathbf{c m}^{2}\right)\end{array}$ & $\begin{array}{r}\text { T }- \\
\text { score }\end{array}$ & $\begin{array}{r}\text { PR } \\
(\boldsymbol{\%})\end{array}$ & $\begin{array}{r}\text { Z- } \\
\text { score }\end{array}$ & $\begin{array}{r}\text { AM } \\
(\%)\end{array}$ \\
L1 & 12.14 & 11.03 & 0.909 & -0.1 & 98 & 0.6 & 108 \\
L2 & 13.38 & 13.56 & 1.014 & -0.1 & 99 & 0.7 & 108 \\
L3 & 13.36 & 12.84 & 0.961 & -1.1 & 89 & -0.3 & 97 \\
L4 & 13.72 & 18.55 & 1.352 & 2.1 & 121 & 3.0 & 133 \\
Total & $\mathbf{5 2 . 6 0}$ & $\mathbf{5 5 . 9 9}$ & $\mathbf{1 . 0 6 4}$ & $\mathbf{0 . 2}$ & $\mathbf{1 0 2}$ & $\mathbf{1 . 0}$ & $\mathbf{1 1 1}$ \\
\hline
\end{tabular}

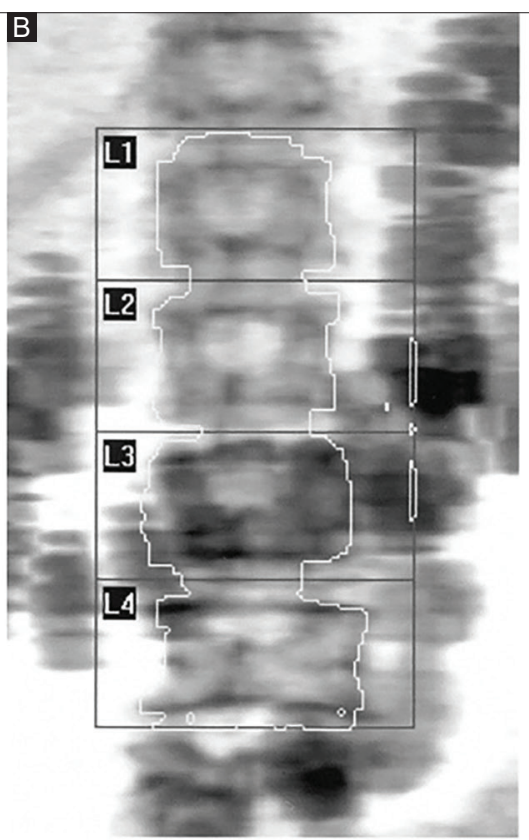

DXA Results Summary:

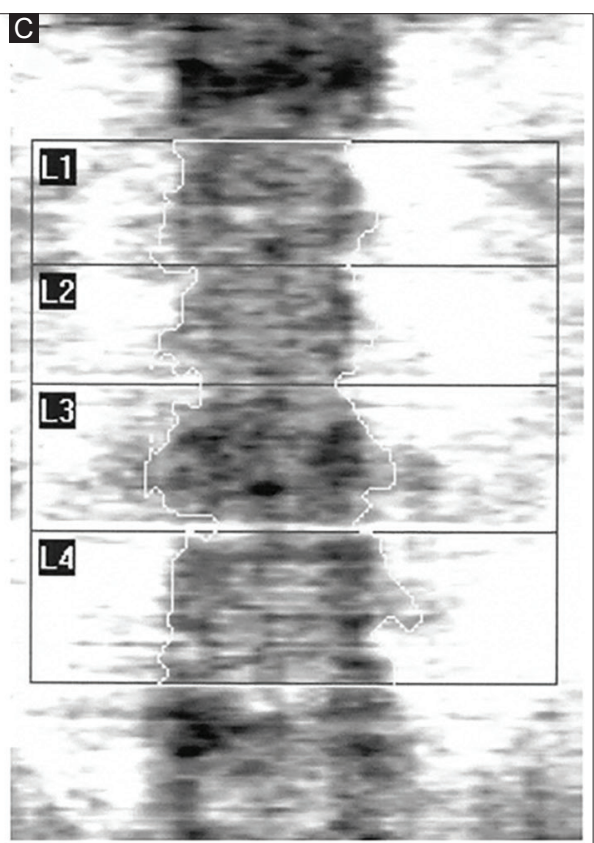

DXA Results Summary:

Figure 1 (A-C): (A) An oval-shaped density from a metallic button of trousers is in ROI of L4, probably mistaken for a focal degenerative process. In densitometric results, the $T$-score of the L4 vertebra is much higher than those of others. (B and $C$ ) Scanning shortly and long after ingestion of the barium for diagnostic radiologic procedures. When recently ingested, the colonic haustrations are readily recognizable. Conversely, long thereafter, barium may be faintly visualized 

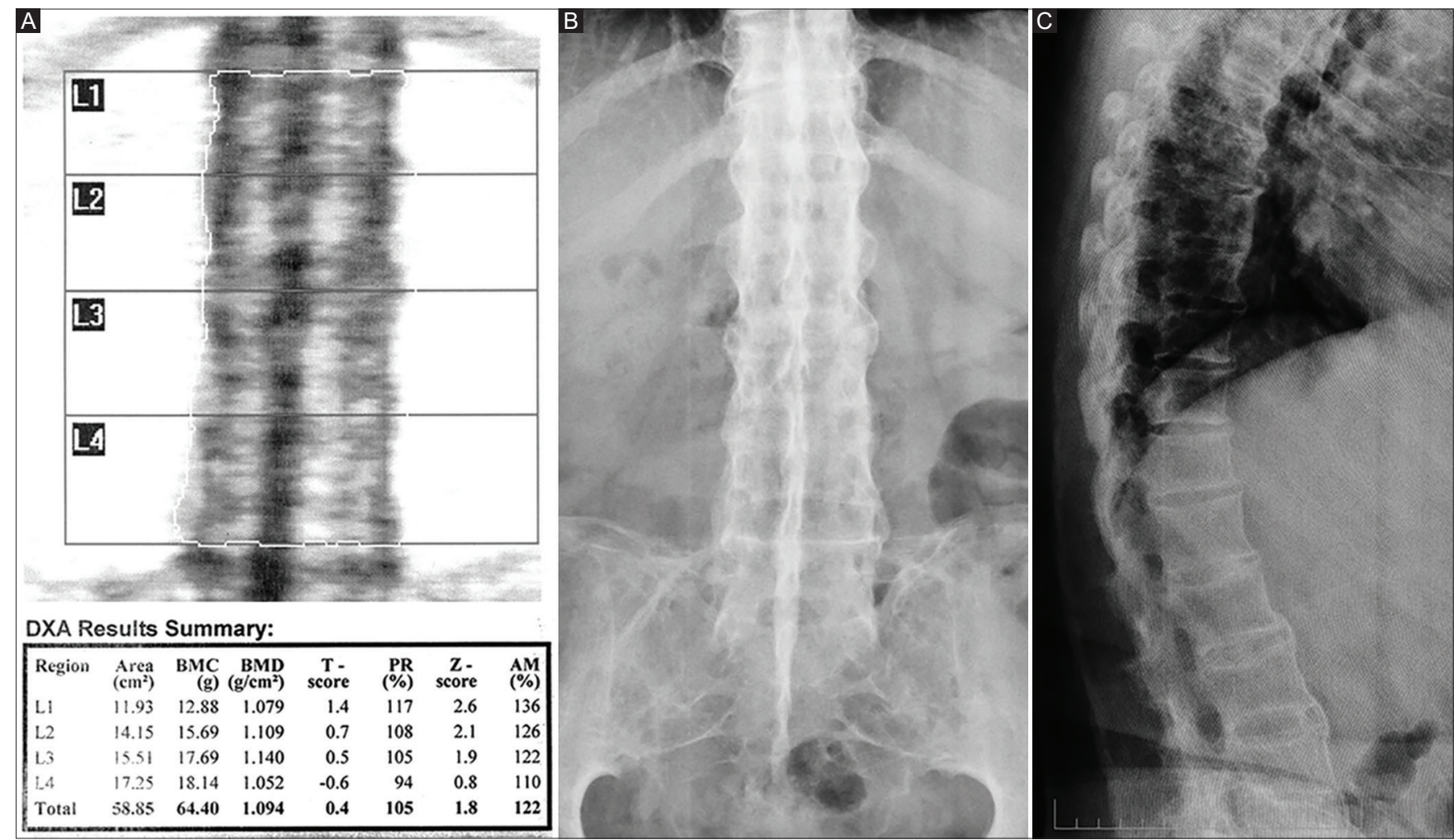

Figure 2 (A-C): (A) DXA scan shows significant fusion of the lumbar vertebrae in a way that vertebrae are poorly delineated. In posteroanterior (B) and lateral $(C)$ views of the plain X-ray images, the classic pattern of AS (as mentioned in the text) is present. In the lateral view, the neighboring vertebrae are fused in anterior aspect of the body through a calcified anterior ligament

\section{Factors Pertinent to Patient Preparation and Conditions/Issues before Scan}

There is a diverse range of conditions and disorders related to the patients undergoing DXA scanning, including skeletal disorders and prior surgeries, which affects densitometric measurement. In this section, the impact of some of the less common and rare skeletal disorders and surgical interventions as well as the effect of poor preparation, for example, recent barium ingestion, and also metallic objects on the patient's garments or pierced to the patient's skin, whether removable or not, are discussed.

Generally recommended, before beginning the procedure, the patient is asked to remove their garments with metallic buttons, zippers, jewelry, or other items with studded metallic objects. They are also asked to empty their pockets of items that may superimpose on the bones at the region of interest and pose a negative impact in the image because of their high density, for example, keys, coins, etc. ${ }^{[1]}$ There are other conditions that may interfere with densitometry which are not removable before the scan. Retained barium in the bowels ingested from radiologic procedures during the past few days is another issue because of interference with the densitometry of the spine. Since the barium in the colonic lumen conforms to the anatomy of the colonic haustrations, the pattern is readily recognizable.
Overlapping on the lumbar vertebrae leads to erroneous measurements and bizarre results. The conditions above should be sought before performing scan through interview with and examination of the patient [Figure 1]..$^{[1-3]}$

An important but rare disorder closely related to the degenerative processes of the bones and joints is ankylosing spondylitis (AS). Inflammation of the skeleton and connective tissues, mainly spine, leads to progressive calcification of the longitudinal ligaments and other peri-spinal soft tissues and joints. When fully developed, the vertebrae cannot be delineated owing to vertebral fusion "bamboo spine" and the calcified ligaments "dagger spine" interfere with densitometric measurements [Figure 2]. ${ }^{[4-6]}$

Lumbar spine and proximal femur are sites frequently involved in metastatic disease. Focal zones with increased mineral density scattered at the regions of interest from osteoblastic or sclerotic neoplasms, that is, prostate or breast cancers, may falsely elevate the overall BMD of that region [Figure 3]. ${ }^{[2,7]}$

Osteoporosis poses the patients at an increased risk of fracture. In lumbar vertebrae, fracture leads to impaction of bony structure and thus elevation in the regional mineral concentration but no change in the absolute mineral content. Patients with compression fracture may undergo 

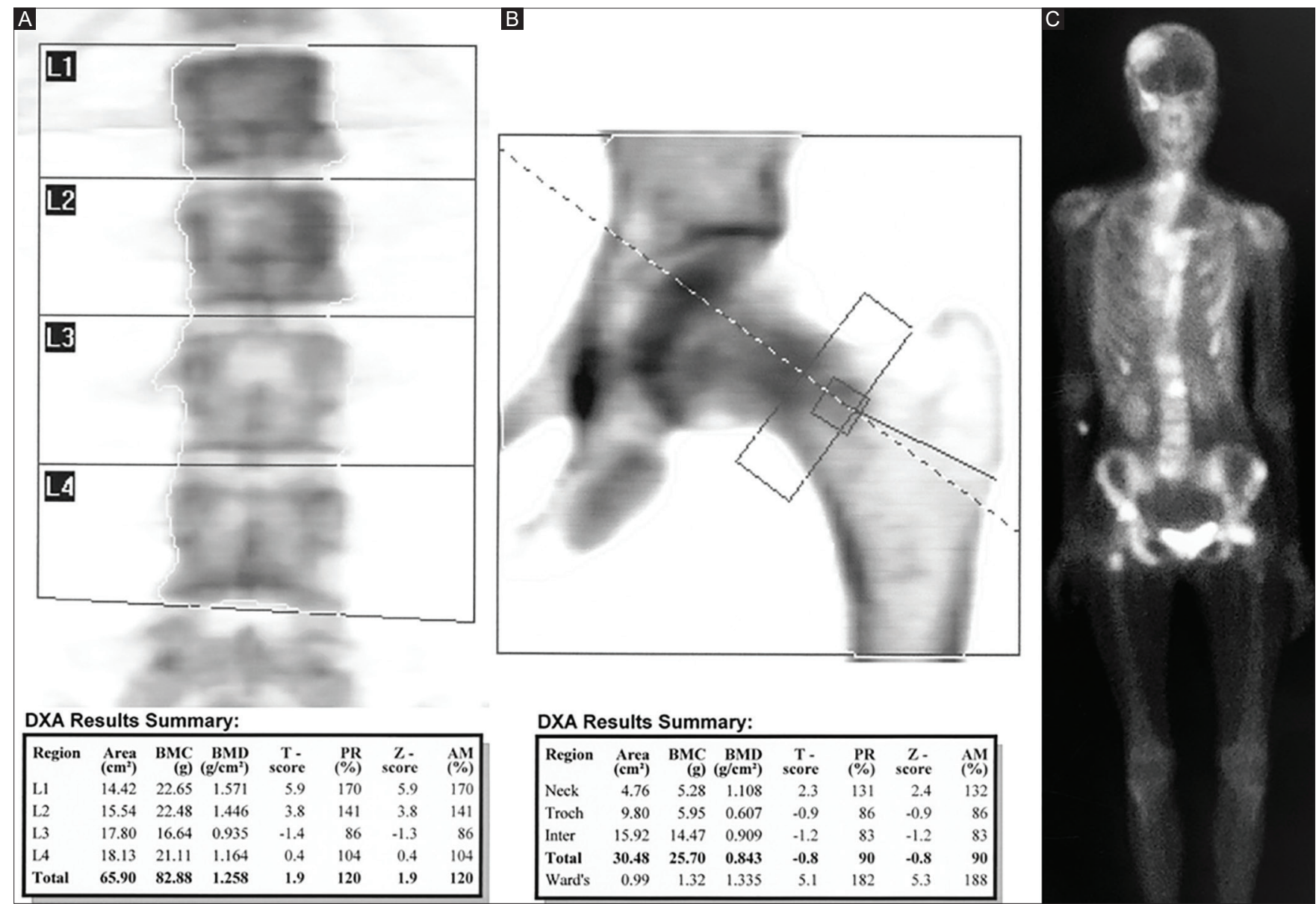

Figure 3 (A-C): (A and B) In the DXA scan, focal zones with higher density are evident in the left hip region. The L1 and L2 vertebrae are also involved totally and partially respectively. In densitometric results, these two vertebrae show significantly higher mineral density and $T$-score. Bone scan $(\mathrm{C})$ confirms the presence of widespread metastatic involvement of the skeleton

vertebroplasty to stabilize the spine through injecting special materials or cement into the vertebral body. On DXA images, the cement is visible as a highly dense material, revealing a far higher attenuation than many nonartificial causes of increased bone density [Figure 4]. ${ }^{[1,8,9]}$

Laminectomy, as surgical removal of lamina and spinous processes of one or more vertebrae, is rarely observed in DEXA scanning but merits an extra attention, because of its consequence in reducing the regional mineral density and thus overdiagnosis [Figure 5]. ${ }^{[2,9]}$

\section{Factors Pertinent to Scan Acquisition}

\section{Positioning}

It is recommended to use standard positioners to place the organ of interest in the correct position suitable for densitometry scanning. Positioning aids include knee positioner and foot restraint or hip positioner. The spine should be placed straight in the middle of the scanning area, without bending or axial rotation. Off-center position of the spine in the scan area should be avoided. Moreover, the natural lordosis of the lumbar spine should be minimized by applying a positioner in order to flex the hip joints at right angle, as close as to $90^{\circ}$. The patient is asked to lay his or her arms out of field of view and not keep them over the stomach. For scanning the hip or femoral regions, a specific positioner is designed and supplied by the manufacturer to strap the foot to, to place the leg internally rotated, by using a Velcro ${ }^{\circ}$ strap. The rationale for such positioning is to make the longitudinal axis of the femoral neck parallel to the detector surface of scanning plane. Thus, the incident photons will hit the bone perpendicularly. Besides, minimum depth of bone tissue and maximum surface are face to the $\mathrm{X}$-ray beam. Lesser trochanter is used as a general and imprecise marker for sufficiency of degree of internal rotation. This standardization helps to maintain consistency of measurements in serial studies as well. Nonconformity to this rule may lead to some changes in the BMD values and thus the diagnosis. Securing the foot to the positioner also minimizes the unintentional movements during scanning. In addition to sufficient internal rotation, the shaft of the femur should be placed straight, parallel to the long axis of the scanning table, without obvious abduction or adduction [Figure 6]. ${ }^{[1,9-14]}$ 

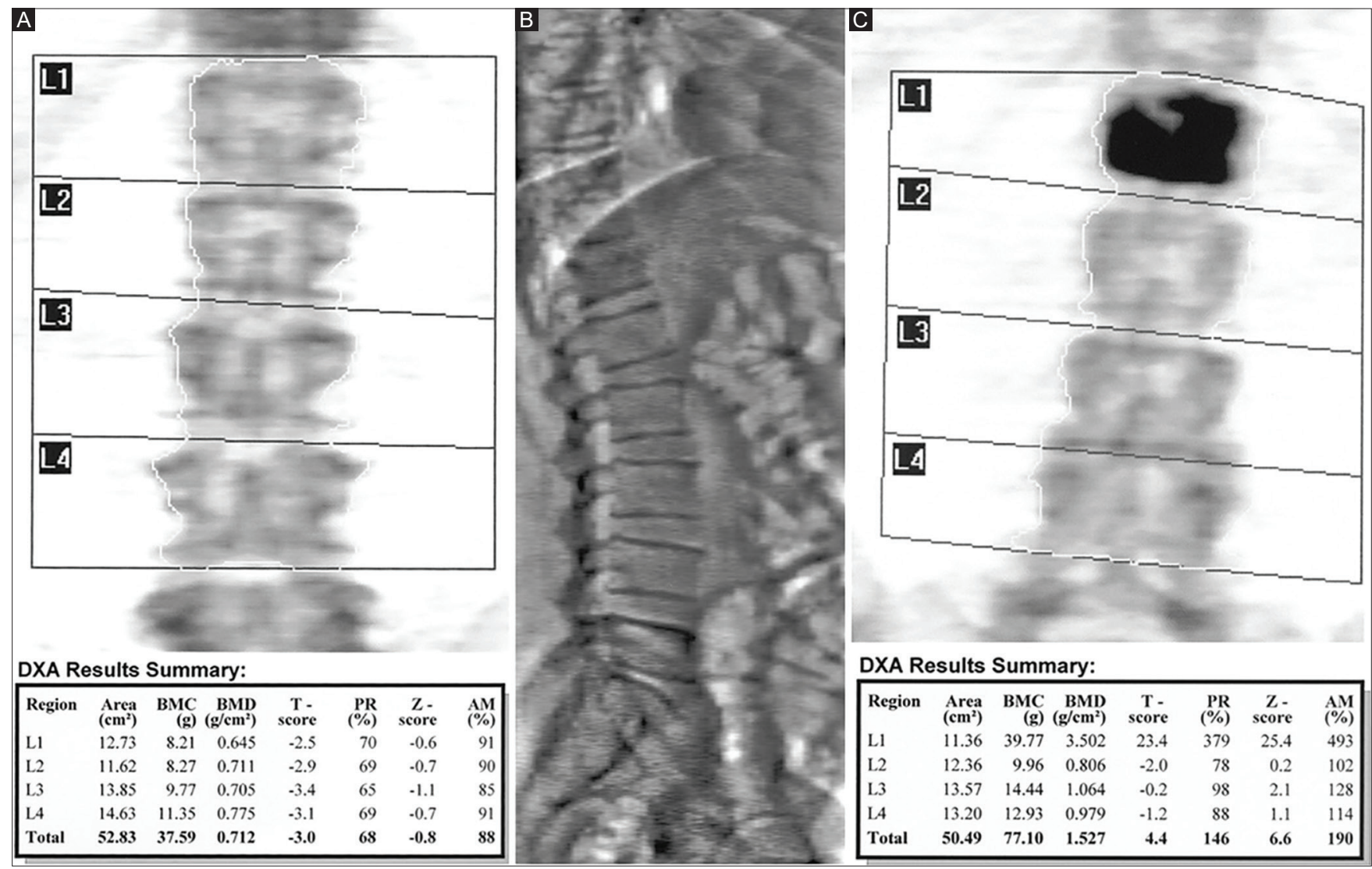

Figure 4 (A-C): (A) With meticulous attention, the higher density of the T12 vertebra may catch the technician's eye. In the lateral view of the spine (B) (IVA or VFA as mentioned in the text) verifies compression fracture in T12 vertebra. (C) A scan with prior vertebroplasty in L1 is presented. The cement placed in the body demonstrates a considerably higher density (a $T$-score of higher than 23 ). These two entities are readily distinguishable

\section{Motion}

The patient should be positioned in a comfortable manner on the scanning table to minimize the probability of occurrence of motion during the scanning. The patient should also be requested to remain still to reduce the potential effect of motion on the densitometric results. A swift jerky movement, voluntary or involuntary as result of cough or sneeze, may be visualized as a break in the bone or "smudge on the image" representing a shift of the pixels. Motion due to breathing may cause the same pattern of image distortion but regular and less severe. The artifact may be appeared as repetitive horizontal lines and breaks in sinusoidal pattern in synchrony with the respiration. Maximization of patient comfort is a helpful tactic to reduce the occurrence of such problem [Figure 7]. ${ }^{[1,10,11]}$

\section{Image noise}

The DXA scanning employs X-ray photons with two different energies, $100 \mathrm{kV}$ and $140 \mathrm{kV}$ in HOLOGIC ${ }^{\circ}$ scanners, to differentiate the bone and soft tissue by providing different attenuation profiles or maps. Ionizing photons bear attenuation while traversing the body tissues of the patient being scanned before detection in the detector. In obese individuals, extra soft tissue superimposed, mainly, on the lumbar spine, strikingly different from patient with average-sized body habitus, may exert an adverse effect on the calculations of the mineral content of the lumbar vertebrae. The uncertainty may even arise as a result of greater amount of noise in the image [Figure 8]. ${ }^{[1,10]}$

\section{Factors Pertinent to Data Processing}

Problems with calibration using quality control phantoms As discussed above, after creation of attenuation profiles by dual-energy photons, to convert the data in the form of attenuation map to bone mineral content (BMC) in grams, a calibration factor is applied, as below equation:

$\operatorname{BMC}(\mathrm{g})=\mu\left(\mathrm{cm}^{-1}\right) \times$ Calibration factor

BMC (g) in every pixel in the DXA image is the product of both factors. This factor is calculated during manufacturing by applying standard phantoms of the spine and hip with known density or its equivalent mineral content based on the specifications of the device, particularly the energy of the $\mathrm{X}$-ray photons, and is installed on the computer of the device. These phantoms simulate those regions in individuals with average body habitus. As long as the daily quality control is passed, the built-in calibration factor is applicable to measurements in clinical setting. As a criterion for proper 


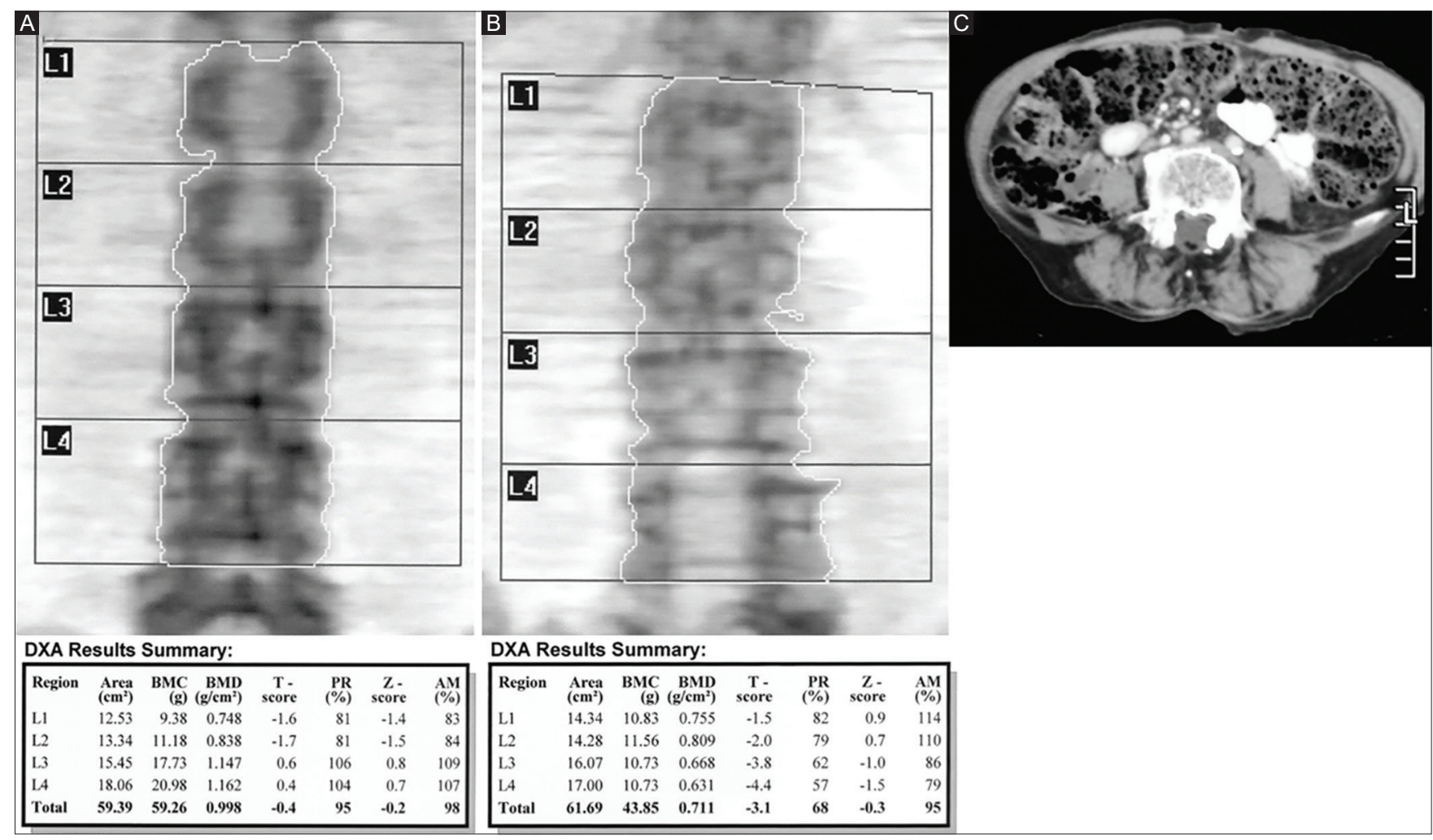

Figure 5 (A-C): (A and B) Two DXA scans with prior laminectomy in upper and lower lumbar spine. These findings may go unnoticed to less experienced eyes. In the densitometric results, the affected vertebrae reveal a considerable decrease in the overall mineral density and $T$-scores and thus misclassified as osteopenia or osteoporosis. (C) The computed tomography at the level of lumbar spine shows absence of the posterior elements of the vertebra

functioning of the device, the result of the QC each day is compared to, say, 10 measurements of calibration during installation of the device as a mean value displayed on the QC plot. These values are used as reference for future data comparisons. Thus, the results of BMD attained by applying an accurate CF depict the clinical factors involved versus the drift of the scanner. A significant deviation of the result of daily QC test, in HOLOGIC ${ }^{\circledR}$ systems, beyond the limits of $\pm 1.5 \%$ of the mean, indicates the need for a new calibration. Fortunately, now, the scanners are equipped with a self-calibration facility to continuously monitor the status and calibrate the device during patient scanning by using a built-in calibration drum, particularly for the variations of the production of the X-ray photons in the tube. Moreover, other sources of error may cause a failed QC test, including improper positioning of the phantom on the scanning table, inaccurate analysis of the image of the scanned phantom, or even as a result of a physical damage in the phantom. It is obvious that every phantom must be used for the device designed and fabricated by the same manufacturer. Although rare, an error in the calculated calibration factor or a change after a major service could result in a systematic error in calculation of BMC [Figure 9]. ${ }^{[10,11]}$

Error in patient data entry

After calculation of the BMC and area, as number of pixels bound by the bone region of interest on the image, the
$\operatorname{BMD}\left(\mathrm{g} / \mathrm{cm}^{2}\right)$ is computed and then is compared with the corresponding values of the normal healthy population embedded in computer as normal reference databases. For spine, the normal reference database includes the information of the vertebrae from L1 to L4 as well as the total and likewise, for the hip, five subregions as neck, trochanteric, intertrochanteric, total, and Ward's area. These databases for spine and hip are constructed from different cohorts of individuals according to gender and ethnicity as well as for different age groups. By means of statistical comparison of the data of an index patient with the databases of the same sex, same race, and either young adult or same age, statistical parameters as $T$ - and Z-scores are generated, respectively. These parameters provide the physician the information of the relative standing of the patient compared to young healthy adults and his or her peers. The data are also presented graphically in the final report based on $T$-score and on the curves based on Z-score. Hence, if the technician fails to select the appropriate gender and ethnicity and also to enter the correct age of the patient or birth date, an unsuitable database is chosen and so that the results are unacceptable. For age, in some countries, specific calendars other than Gregorian calendar may be in use and thus the inter-calendar conversion of date of birth may cause occasional mistake. Lack of data or erroneous information regarding menopausal status in female patients lead to inappropriate selection of available criteria, WHO versus 

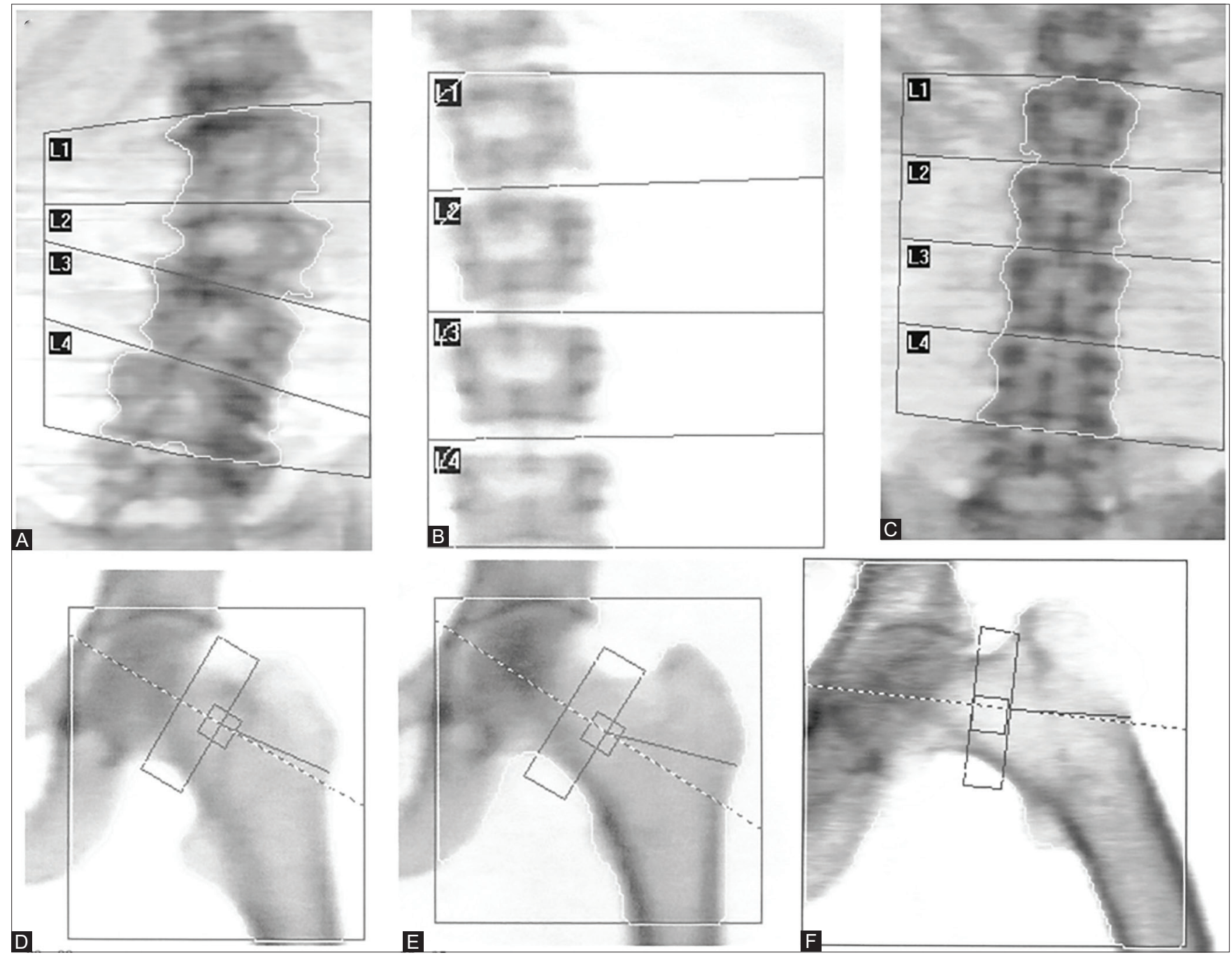

Figure $6(A-F)$ : Various mispositioning of the spine and hip; marked spinal bending as a result of degeneration (A), off-center spine during acquisition (B), patient's hands resting on the chest resembling the ribs (C), insufficient (D), and sufficient (E) internal rotation of the leg, striking abduction of the leg (F)

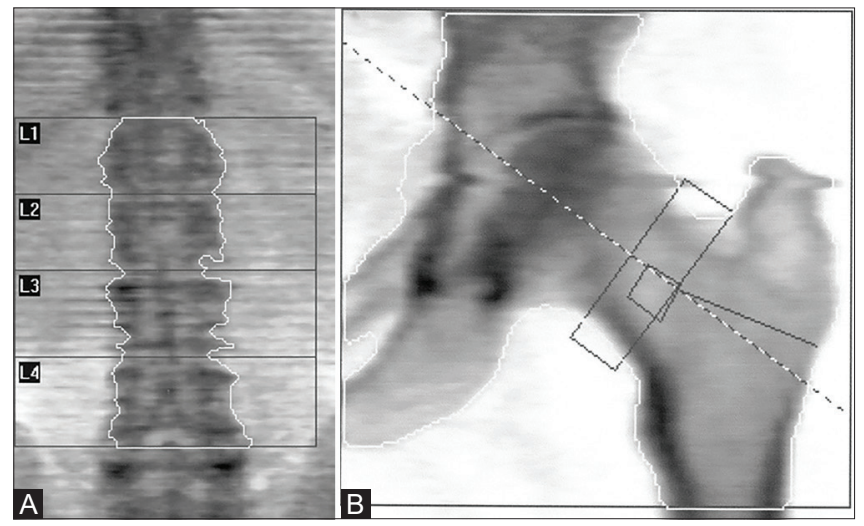

Figure 7 ( $A$ and $B$ ): (A) Regular horizontal lines during the scan as a result of rapid deep breathing of the patient. (B) A swift jerky movement occurred almost in the middle of the scanning of the hip region. The pattern is similar to a smudge on the image from right to left

ISCD, for diagnostic classification and also for estimation of the fracture risk by FRAX ${ }^{\circledR}$ algorithm [Figure 10]..$^{[10-12]}$

\section{ROI placement and Bone map error}

After checking the quality of scan, an important step is placing the regions of interest. In lumbar spine, the vertebrae must be recognized and labeled correctly based on the site of the attachment of the 12th ribs, level of iliac crests, and also the configuration of the vertebrae. Then, the whole or global ROI and intervertebral lines should be placed accordingly. The next step, which plays even a more critical role, is drawing the bone map. In this process, which is associated with the concept of segmentation in image processing, the edges of the bones are detected automatically and thus the bone is separated from the neighboring soft tissue. Least operator intervention in this process maximizes the reproducibility in serial scans. Before proceeding to analysis and generating the result, the technician must verify the correctness of the bone map. Minor errors like small holes, remained at the region of bone map or small zones or "islands" mapped as bone outside the bone map, are less critical to be resolved. However, there are options 
in dedicated software packages that automatically resolve them, for instance, in HOLOGIC ${ }^{\circ}$ software, "Fill Holes" and "Sink Islands" are designed for such problems. Any major error in mapping of a bone may lead to a notable change in the area and therefore the bone mineral density of that bone. In some occasions, as a result of decreased mineral content of the bone, differentiation from the neighboring soft tissue may be compromised. Therefore, the corresponding bone

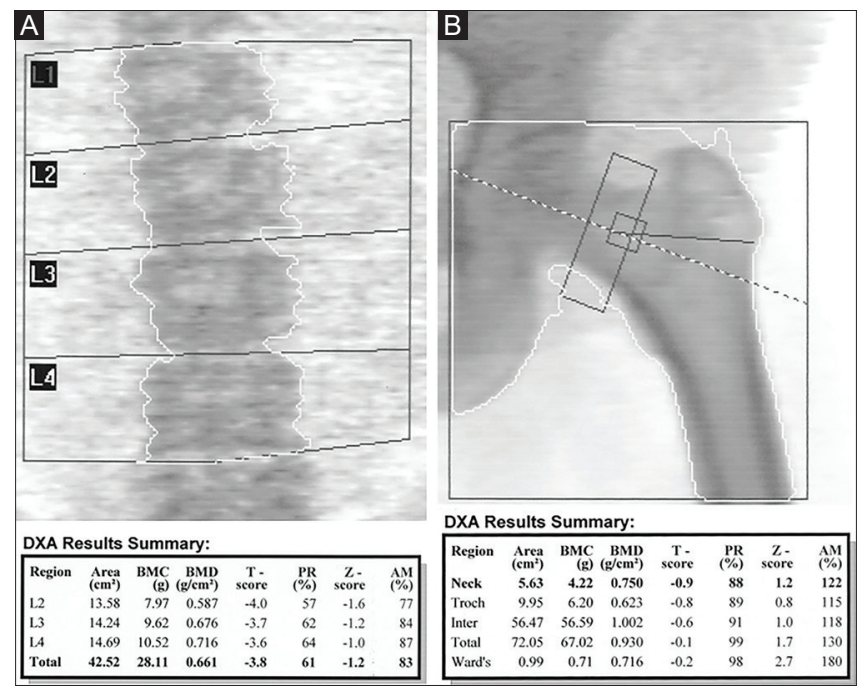

Figure $\mathbf{8}$ ( $A$ and $B$ ): (A) In this obese patient, the image of the lumbar spine seems grainy in texture and also the edges of the bony tissues seem like irregular sawtooth. (B) Substantial amount of fat of the abdomen is superimposed on the iliac bone and femoral head and neck. As can be seen, these regions show grainy texture as well, but the remaining part of the femur reveals a uniform and smooth appearance. When a high amount of soft tissue is overlapped on the regions of interest, the contouring may be compromised and thus some parts of soft tissue may be included in the bone map (shown by arrowhead) may not be correctly mapped and some parts may be cut out. Conversely, parts of soft tissue may be included in the map of bone. All this issues result in erroneous density measurements and requires manual correction by the operator [Figures 11 and 12]. $\cdot^{[9-13]}$

\section{Conclusion/Take-Home Messages}

Correct technique of conducting DXA scans is prior to and a prerequisite for a correct interpretation. In DXA scanning, factors that are able to potentially affect the results may be organized in three different categories, including preparation, acquisition, and processing. In each category, there are multiple factors, as listed above, that create uncertainties and fallacies to different extents. Some are visualized as an imaging artifact in the DXA

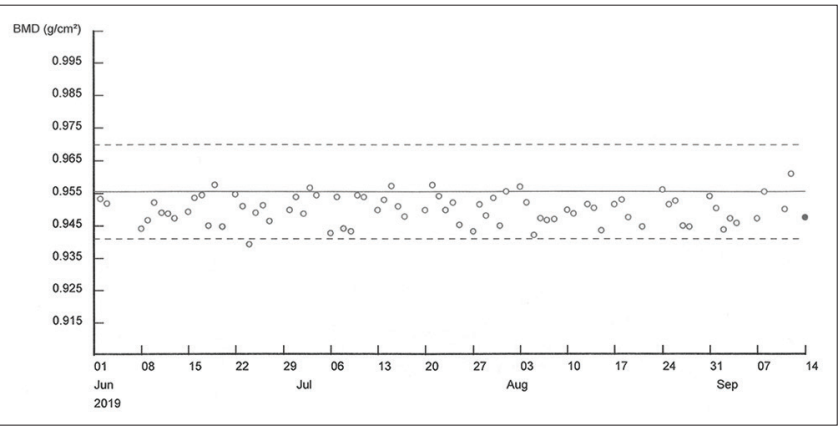

Figure 9: Plot of daily QC using spine phantom from June 1 to September 14. Vertical axis denotes the BMD of the phantom and the horizontal axis represents time. Each circle corresponds to the result of a specific day. Preferably, the circles should lay between two horizontal lines (dashed lines) as 95\% confidence interval around the mean (solid horizontal line) measured during installation. The solid circle signifies the result of the last day the QC procedure is performed

\section{DXA Results Summary:}

\begin{tabular}{|lrrrrrrr|}
\hline Region & $\begin{array}{r}\text { Area } \\
\left(\mathbf{c m}^{2}\right)\end{array}$ & $\begin{array}{r}\text { BMC } \\
(\mathbf{g})\end{array}$ & $\begin{array}{r}\mathbf{B M D} \\
\left(\mathbf{g} / \mathbf{c m}^{2}\right)\end{array}$ & $\begin{array}{r}\mathrm{T}- \\
\text { score }\end{array}$ & $\begin{array}{r}\mathrm{PR} \\
(\mathbf{\%})\end{array}$ & $\begin{array}{r}\mathrm{Z}- \\
\text { score }\end{array}$ & $\begin{array}{r}\text { AM } \\
(\%)\end{array}$ \\
Neck & $\mathbf{4 . 5 2}$ & $\mathbf{2 . 6 4}$ & $\mathbf{0 . 5 8 4}$ & $\mathbf{- 2 . 4}$ & 69 & -1.5 & $\mathbf{7 8}$ \\
Troch & 9.46 & 4.42 & 0.467 & -2.3 & 66 & -1.8 & 72 \\
Inter & 13.29 & 10.69 & 0.804 & -1.9 & 73 & -1.5 & 77 \\
Total & 27.28 & 17.75 & 0.651 & -2.4 & 69 & -1.8 & 75 \\
Ward's & 1.11 & 0.53 & 0.476 & -2.2 & 65 & -0.7 & 86 \\
\hline
\end{tabular}

DXA Results Summary:

\begin{tabular}{|lrrrrrrr|}
\hline Region & $\begin{array}{r}\text { Area } \\
\left(\mathbf{c m}^{2}\right)\end{array}$ & $\begin{array}{r}\text { BMC } \\
(\mathbf{g})\end{array}$ & $\begin{array}{r}\text { BMD } \\
\left(\mathrm{g} / \mathrm{cm}^{2}\right)\end{array}$ & $\begin{array}{r}\text { T- } \\
\text { score }\end{array}$ & $\begin{array}{r}\text { PR } \\
(\%)\end{array}$ & $\begin{array}{r}\text { Z- } \\
\text { score }\end{array}$ & $\begin{array}{r}\text { AM } \\
(\%)\end{array}$ \\
Neck & $\mathbf{5 . 1 8}$ & $\mathbf{4 . 0 2}$ & $\mathbf{0 . 7 7 6}$ & $-\mathbf{1 . 1}$ & $\mathbf{8 3}$ & $\mathbf{0 . 4}$ & 108 \\
Troch & 11.21 & 8.01 & 0.714 & -0.5 & 92 & 0.2 & 105 \\
Inter & 22.06 & 25.11 & 1.138 & -0.3 & 95 & 0.7 & 113 \\
Total & 38.45 & 37.14 & 0.966 & -0.4 & 93 & 0.6 & 111 \\
Ward's & 1.24 & 0.99 & 0.801 & 0.1 & 102 & 2.4 & 174 \\
\hline
\end{tabular}

\section{DXA Results Summary:}

\begin{tabular}{|lrrrrrrr|}
\hline Region & $\begin{array}{r}\text { Area } \\
\left(\mathbf{c m}^{2}\right)\end{array}$ & $\begin{array}{r}\text { BMC } \\
(\mathrm{g})\end{array}$ & $\begin{array}{c}\text { BMD } \\
\left(\mathrm{g} / \mathrm{cm}^{2}\right)\end{array}$ & $\begin{array}{r}\text { T }- \\
\text { score }\end{array}$ & $\begin{array}{r}\text { PR } \\
(\%)\end{array}$ & $\begin{array}{r}\mathrm{Z}- \\
\text { score }\end{array}$ & $\begin{array}{r}\text { AM } \\
(\%)\end{array}$ \\
Neck & $\mathbf{4 . 5 2}$ & $\mathbf{2 . 6 4}$ & $\mathbf{0 . 5 8 4}$ & $\mathbf{- 2 . 4}$ & $\mathbf{6 9}$ & $\mathbf{- 2 . 0}$ & $\mathbf{7 2}$ \\
Troch & 9.46 & 4.42 & 0.467 & -2.3 & 66 & -2.2 & 68 \\
Inter & 13.29 & 10.69 & 0.804 & -1.9 & 73 & -1.8 & 74 \\
Total & 27.28 & 17.75 & 0.651 & -2.4 & 69 & -2.2 & 71 \\
Ward's & 1.11 & 0.53 & 0.476 & -2.2 & 65 & -1.5 & 74 \\
\hline
\end{tabular}

\section{DXA Results Summary:}

\begin{tabular}{|lrrrrrrr|}
\hline Region & $\begin{array}{r}\text { Area } \\
\left(\mathbf{c m}^{2}\right)\end{array}$ & $\begin{array}{r}\text { BMC } \\
(\mathbf{g})\end{array}$ & $\begin{array}{r}\text { BMD } \\
\left(\mathrm{g} / \mathrm{cm}^{2}\right)\end{array}$ & $\begin{array}{r}\text { T - } \\
\text { score }\end{array}$ & $\begin{array}{r}\text { PR } \\
(\%)\end{array}$ & $\begin{array}{r}\mathrm{Z}- \\
\text { score }\end{array}$ & $\begin{array}{r}\text { AM } \\
(\%)\end{array}$ \\
Neck & $\mathbf{5 . 1 8}$ & $\mathbf{4 . 0 2}$ & $\mathbf{0 . 7 7 6}$ & $\mathbf{- 0 . 7}$ & $\mathbf{9 1}$ & $\mathbf{1 . 7}$ & $\mathbf{1 3 2}$ \\
Troch & 11.21 & 8.01 & 0.714 & 0.1 & 102 & 1.9 & 137 \\
Inter & 22.06 & 25.11 & 1.138 & 0.2 & 103 & 2.1 & 140 \\
Total & 38.45 & 37.14 & 0.966 & 0.2 & 103 & 2.3 & 141 \\
Ward's & 1.24 & 0.99 & 0.801 & 0.6 & 109 & 3.6 & 211 \\
\hline
\end{tabular}

Figure 10: Bone mineral density results of the proximal femur of a patient aged 52 (top left) and the results when date of birth is mistakenly entered (here, age of 42) (top right). As can be seen, $T$-scores remained the same but $Z$-scores decreased as the patient data are compared to younger healthy adults. Data of a male patient (bottom left) compared to that when the sex is entered as female. The $T$ - and $Z$-scores are increased. These errors result in, occasionally, a change in the diagnosis 


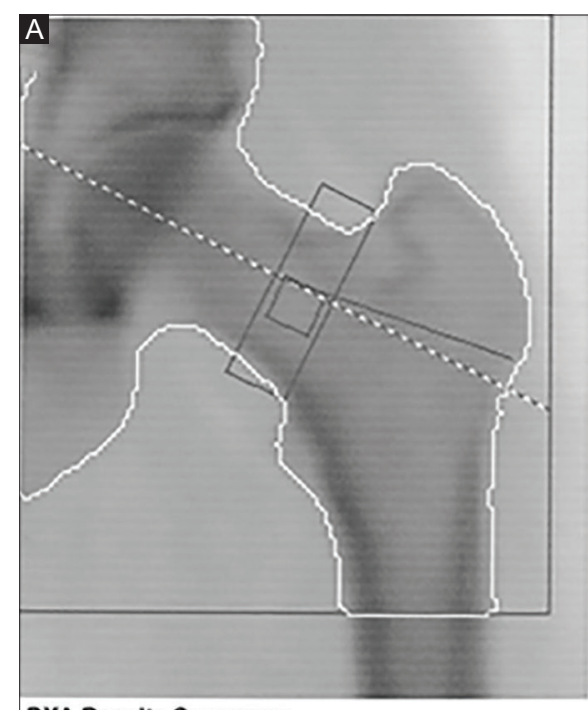

DXA Rosults Summary:

\begin{tabular}{|c|c|c|c|c|c|c|c|}
\hline Rexion & $\begin{array}{l}\text { Arra } \\
\text { (cer') }\end{array}$ & $\begin{array}{r}\text { BNGC } \\
(\text { ) }\end{array}$ & $\begin{array}{l}\text { BMD } \\
\text { (cm') }\end{array}$ & rere & PR & zere & (\%) \\
\hline rok & 5.26 & 1.6 & $0 \times 66$ & a.s & 93 & -0.1 & 9 \\
\hline 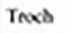 & 12.6 & 9.91 & 0. & 0.1 & 102 & 0.3 & 105 \\
\hline \& & 23.64 & 27.51 & 1. & $-a 2$ & 97 & -0.1 & 98 \\
\hline & 41.4 & 41.98 & 1.0 & -0.1 & 98 & 0 & 100 \\
\hline and & 1.07 & 0.79 & 0.739 & -3.3 & 94 & 0.3 & 106 \\
\hline
\end{tabular}

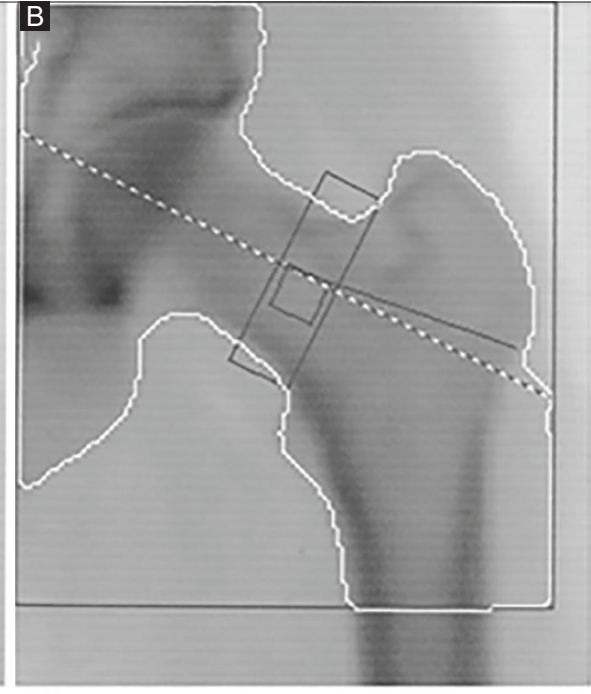

DXA Rosults Summary:

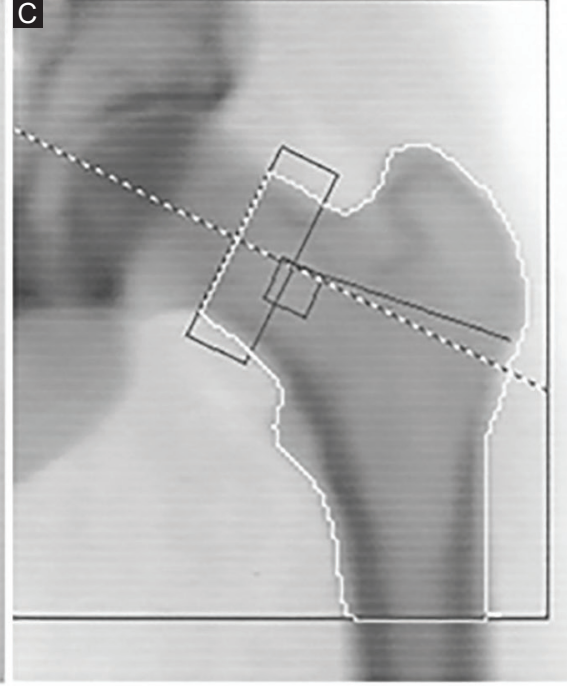

OXA Rosults Summary:

\begin{tabular}{|c|c|c|c|c|c|c|c|c|c|c|c|c|c|c|c|}
\hline Rogion & (rras') & ${ }_{(\mathbb{C})}^{B M C}$ & $\begin{array}{c}\text { RNID } \\
\left(\mathrm{o}^{\prime} \mathrm{km}^{\prime}\right)\end{array}$ & Trore & $\begin{array}{l}P R \\
(\%)\end{array}$ & $\underset{\text { scere }}{Z \text {. }}$ & $\hat{(*)}$ & Rexiona & (cma & Buc & $\underset{\left(0^{\prime} \mathbf{r m}\right)}{\text { BNID }}$ & Trere & $\begin{array}{l}P R \\
(\%)\end{array}$ & Z. & (\%) \\
\hline Nirkh & S24 & +15 & ascos & .0 .5 & 93 & -0.1 & 90 & $\sin t$ & & & & & & & \\
\hline Troesh & 12.46 & 9.93 & 0.791 & 0.1 & 102 & 0.3 & 105 & Toxs & & & & & & & \\
\hline theser & 20.55 & 30.74 & 1.040 & -0.9 & 87 & -0.8 & 88 & Intere & 0.59 & 0.41 & 0.200 & -2.7 & 59 & -2.7 & 59 \\
\hline Teed & 47.35 & 45.22 & 0.955 & 0.5 & 92 & -0.4 & 94 & Total & ass & a.11 & 0.700 & -2.2 & 68 & -2.1 & $\theta$ \\
\hline Wanss & 1.07 & $a>y$ & 0.720 & .0 .3 & 94 & 0.3 & 106 & W'anss & ass & 0.0 & 0.727 & -0.4 & 93 & 0.2 & 104 \\
\hline
\end{tabular}

Figure 11 (A-C): (A) The region of interest and bone map is placed correctly. (B) The ROI and bone map drawn initially by automatic option of software. Some parts of soft tissue adjacent femoral shaft are included. This finding seems subtle enough to remain hidden from a technician's or physician' eyes. The consequence is evident in the density and T-score of the total femur compare to corresponding values in (A). (C) Another analysis of the hip region of the same patient by the software excluded some necessary parts of the hip. In such situations, no data would be available in the table of densitometric results
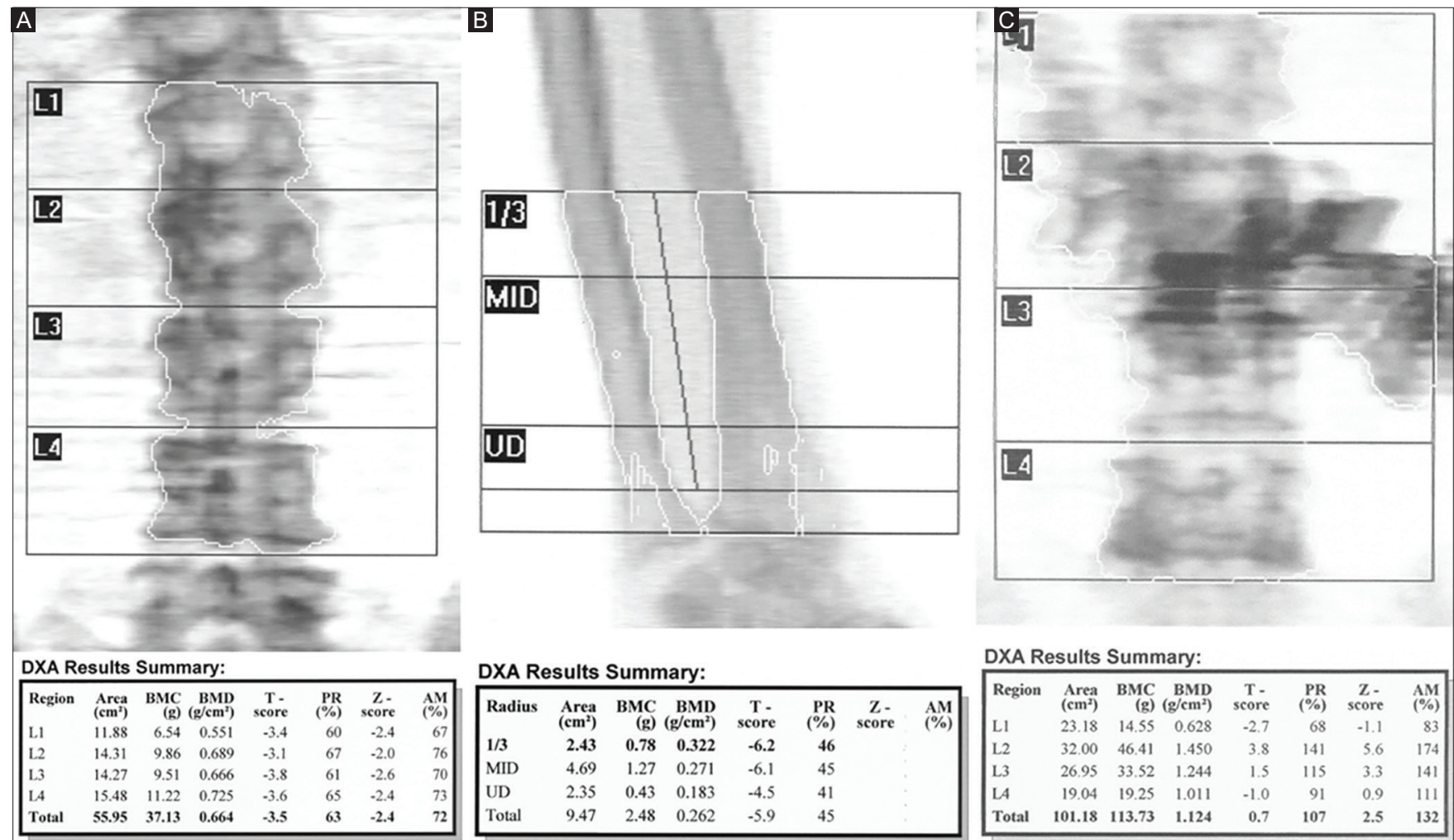

DXA Results Summary:
\begin{tabular}{|lrrrrrrr|}
\hline Radius & $\begin{array}{r}\text { Area } \\
\left(\mathbf{c m}^{2}\right)\end{array}$ & $\begin{array}{r}\text { BMC } \\
(\mathbf{g})\end{array}$ & $\begin{array}{c}\text { BMD } \\
\left(\mathbf{g} / \mathbf{c m}^{2}\right)\end{array}$ & $\begin{array}{r}\text { T - } \\
\text { score }\end{array}$ & $\begin{array}{r}\text { PR } \\
(\mathbf{\%})\end{array}$ & $\begin{array}{c}\text { Z- } \\
\text { score }\end{array}$ & $\begin{array}{c}\text { AM } \\
(\%)\end{array}$ \\
$\mathbf{1 / 3}$ & $\mathbf{2 . 4 3}$ & $\mathbf{0 . 7 8}$ & $\mathbf{0 . 3 2 2}$ & $\mathbf{- 6 . 2}$ & $\mathbf{4 6}$ & & \\
MID & 4.69 & 1.27 & 0.271 & -6.1 & 45 & & \\
UD & 2.35 & $\mathbf{0 . 4 3}$ & 0.183 & -4.5 & 41 & & \\
Total & 9.47 & 2.48 & 0.262 & -5.9 & 45 & & \\
\hline
\end{tabular}

DXA Results Summary:
\begin{tabular}{|lrrrrrrr|}
\hline Region & $\begin{array}{r}\text { Area } \\
\left(\mathrm{(m}^{2}\right)\end{array}$ & $\begin{array}{r}\text { BMC } \\
(\mathrm{g})\end{array}$ & $\begin{array}{r}\text { BMD } \\
\left(\mathbf{g} / \mathbf{c m}^{2}\right)\end{array}$ & $\begin{array}{r}\text { T- } \\
\text { score }\end{array}$ & $\begin{array}{r}\text { PR } \\
(\%)\end{array}$ & $\begin{array}{r}\text { Z- } \\
\text { score }\end{array}$ & $\begin{array}{r}\text { AM } \\
(\%)\end{array}$ \\
L1 & 23.18 & 14.55 & 0.628 & -2.7 & 68 & -1.1 & 83 \\
L2 & 32.00 & 46.41 & 1.450 & 3.8 & 141 & 5.6 & 174 \\
L3 & 26.95 & 33.52 & 1.244 & 1.5 & 115 & 3.3 & 141 \\
L4 & 19.04 & 19.25 & 1.011 & -1.0 & 91 & 0.9 & 111 \\
Total & $\mathbf{1 0 1 . 1 8}$ & $\mathbf{1 1 3 . 7 3}$ & $\mathbf{1 . 1 2 4}$ & $\mathbf{0 . 7}$ & $\mathbf{1 0 7}$ & $\mathbf{2 . 5}$ & $\mathbf{1 3 2}$ \\
\hline
\end{tabular}

Figure $12(A-C)$ : $(A)$ In this image, some parts of the bone are excluded from the bone map as a result of significant hypodensity of the bone. The consequence is false elevation of the bone mineral density and T-score. (B) Similar findings in the forearm region as that in (A). (C) The patient has ingested barium and now the barium in the transverse colon overlaps the lumbar spine. The vertebral lines are drawn correctly but the bone map includes areas with barium retention in the colon as parts of bony tissues 
image and others may be inferred and understood from the quantitative results. High-density materials, metallic objects in or attached to body/garments, falsely increase BMD values due to higher radiation attenuation. Retained barium in bowels, if overlapped on the vertebrae, metastatic lesions in skeleton and vertebral compression fracture and vertebroplasty causes increase in BMD. Conversely, laminectomy leads to decrease in BMD. Positioning may change BMD values and diagnosis and also causes inconsistency of measurements in serial studies. ROI placement and bone map error by both erroneous soft tissue inclusion and bone exclusion during bone mapping make changes in BMD of a bone or bone subregion. To avoid such misleading interpretation, attempt to acquire a substantial pertinent knowledge is undeniable for daily good practice for both physicians and technologists.

\section{Financial support and sponsorship}

Nil.

\section{Conflicts of interest}

There are no conflicts of interest.

\section{References}

1. Dual Energy X Ray Absorptiometry for Bone Mineral Density and Body Composition Assessment. Vienna: International Atomic Energy Agency; 2011.

2. Martineau P, Bazarjani S, Zuckier LS. Artifacts and incidental findings encountered on Dual-energy X-Ray absorptiometry: Atlas and analysis. Semin Nucl Med 2015;45:458-69.
3. Spencer RP, Malcolm DM, Barton PA. Totem pole sign. Bone densitometry study with retained barium. Clin Nucl Med 1991;16:596.

4. Proft F, Poddubnyy D. Ankylosing spondylitis and axial spondyloarthritis: Recent insights and impact of new classification criteria. Ther Adv Musculoskelet Dis 2018;10:129-39.

5. Vasdev V, Bhakuni D, Garg MK, Narayanan K, Jain R, Chadha D. Bone mineral density in young males with ankylosing spondylitis. Int J Rheum Dis 2011;14:68-73.

6. Magrey MN, Lewis S, Asim Khan M. Utility of DXA scanning and risk factors for osteoporosis in ankylosing spondylitis-A prospective study. Semin Arthritis Rheum 2016;46:88-94.

7. Paccou J, Michou L, Kolta S, Debiais F, Cortet B, Guggenbuhl P. High bone mass in adults. Joint Bone Spine 2018;85:693-9.

8. Aparisi F. Vertebroplasty and kyphoplasty in vertebral osteoporotic fractures. Semin Musculoskelet Radiol 2016;20:382-91.

9. Watts NB. Fundamentals and pitfalls of bone densitometry using Dual-energy X-ray absorptiometry (DXA). Osteoporos Int 2004;15:847-54.

10. QDR reference manual. Document No. MAN-01016 Revision 003. Hologic, Inc.; 2009.

11. Dual Energy X-ray Absorptiometry (DXA) Procedures Manual. National health and nutrition examination survey (NHANES). 2007. Available from: https://www.cdc.gov/nchs/data/nhanes/ nhanes_07_08/manual_dexa.pdf. [Last accessed on 2019 Nov 05].

12. Morgan SL, Prater GL. Quality in Dual-energy X-ray absorptiometry scans. Bone 2017;104:13-28.

13. Theodorou DJ, Theodorou SJ. Dual-energy X-ray absorptiometry in clinical practice: Application and interpretation of scans beyond the numbers. Clin Imaging 2002;26:43-9.

14. Qutbi M, Salek A, Soltanshahi M, Ajdari SE, Asli IN. The impact of nonstandard hip rotation on densitometric results of hip regions and potential misclassification of diagnosis. Arch Osteoporos 2019;14:86. 